\title{
Impact of Biomass Transformation Efficiency on the Energy Consumption Pattern of the Building Sector
}

\author{
Joseph Ebako1
}

Department of Energy Studies, Graduate School of International Studies, Ajou University, 206 Ajou University Street, Suwon City, Gyeonggi-do, South Korea

\begin{abstract}
The building sector of most tropical countries still use predominantly primary biomass as the principal fuel. This has adverse effects like $\mathrm{CO}_{2}$ emission and deforestation and is associated with issues like poverty, ill-health, and low standard of living. Therefore, energy policies try to improve on the efficiency of firewood and charcoal end-use technologies, to palliate the negative effects. In this research, the global change assessment model (GCAM) is used, to investigate the impact of efficiency improvement on the energy consumption pattern of the building sector of developing countries. The aim of the study is to provide empirical data that would better inform policy makers on the effects of modernizing these primary fuels. The study developed three scenarios with different levels of efficiency improvements. The results show that efficiency improvement rather increases primary biomass consumption and $\mathrm{CO} 2$ emission. However, there is fall in the consumption of traditional biomass in the second half of the modelling period. The increase in biomass-based fuels consumption was seen to be linked to their affordability. Therefore, policy makers need not only elaborate policies that improve biomass efficiency, but also introduce and motivate other clean cooking fuels like butane, biogas, and electricity.
\end{abstract}

Keywords: energy modeling, biomass transformation efficiency, global change assessment model, integrated assessment model, cooking fuel

\section{Introduction}

Many developing countries in their fight to grow economically, realize that energy security is the cornerstone to economic development. More so, ensuring access to clean and affordable energy is a key objective for many international organizations [1]. One of the aspects of energy security, affordability, is directly linked to key global challenges namely: poverty alleviation, climate change, and food security [2]. In a report by the UNDP and the World Bank back in the 80s, it was already clear that that developing country ought to invest in and develop their most available indigenous energy resources [3]. For most developing countries, especially in those in the equatorial forest belt, that resource is biomass.

In Cameroon, biomass is the major final energy form and is used mostly by the building sector for heating and cooking, and mostly by the rural population [4]. Furthermore, electricity production is mainly by hydroelectricity $(51 \%)$ and fossil fuel ( $48 \%$ ) the remaining $1 \%$ is shared between solar, wind, and biomass [4]. However, hydroelectricity is very susceptible to climate with some years having very low production due to low precipitation. Even so, the fleeting oil reserve of Cameroon poses a great threat to its energy security as the country may become entirely an oil importer in less than a decade $[5,6]$. With this situation, if developing the biomass resource can help Cameroon to solve its energy issues, it would therefore be important to demonstrate to the decision-makers with empirical evidence, why energy policies should be geared towards developing technologies and investing in biomass transformation projects [7] and this would affect the energy system in the long run.

The abundant availability and widespread use of biomass in developing countries for energy purposes has inspired lots of studies on various biomass applications and to analyze the impact of such

${ }^{1}$ Present Address: Department of Renewable Energy and Energy Management, Ministry of Water and Energy,

P.O. Box 70, Yaoundé, Cameroon,

Email: ebakojoseph@gmail.com,

Telephone: +(237) 674734473 
applications on the environment and economy, and in particular, the energy sector. According to previous studies, biomass will remain the main energy source for residences in developing countries for decades to come [8]. Different factors influence the demand for biomass, namely: economic, geographic, and household dwelling and family characteristics, and most importantly, the household expenditure per capita [9]. Besides heating and cooking, there are numerous ways to convert biomass into useful energy, chemicals, or mechanical and electrical power [10]. Gasification, for example, is a process whereby biomass is treated with heat to produce gaseous fuel called syngas, which could be used for electricity production in gas turbines or internal combustion engines [11]. Furthermore, the real cost of energy for rural homes who produce their energy (by wood and dung collection), could be reduced by $70 \%$, while saving an average of 6 hours of labor per week and provide manure for agricultural purposes, if households could implement a biomass-to-biogas project to replace traditional fuels [12]. This is because these modern and more efficient technologies have higher conversion efficiencies, of about $55 \%$ for biogas utilization, compared to $15 \%$ conversion efficiency associated with the traditional open-fire firewood consumption [13], [14],[15].

Within the context of climate change, studies show that rural residences consume less energy compared to the residences in urban areas, but pollute more due to their final energy form which is mostly traditional biomass [16]. In addition, the use of firewood by households for energy leads to increasing deforestation rates [5]. However, improving biomass exploitation technologies would lead to about $60 \%$ biomass savings thereby encouraging sustainable biomass usage [17]. Further, looking at the energy consumption patterns for rural households, some specific technological, policy, institutional, and political issues of the rural population must be addressed for appropriate energy problem resolution [7]. Therefore, there is a need of introducing new energy policies and institutional modifications to improve the performance of energy initiatives for rural development, which is the case for most developing countries [18]. Some studies based on statistical evaluation showed that increase biomass consumption led to reduced $\mathrm{CO}_{2}$ emission in the US, however, there are no energy modelbased studies have studied the link between efficiency, this subject for regions with intensive biomass consumption in the building sector, such as developing countries.

The focus of this study is the influence of biomass technology efficiency on the fuel consumption patterns of the building sector and to evaluate the effect on $\mathrm{CO}_{2}$ emission. Affordability of fuel, which is the main factor that determines the consumption pattern, is the ratio between the average per capita income and the price of the fuel [19]. Modeling the building sector using GCAM makes use of the already existing building sector model contained within GCAM. According to the SSP4, energy consumption is driven by the demand for services (heating, cooling, etc.) and service demands for residential and commercial floor space are indicators of the growth in demand for building fuels [20].

\section{Methods and Data}

\subsection{Methods}

In this study, GCAM was used to model the energy system of Cameroon. The model is flexible, and accommodates detailed technological aspects, yet it works well with the sparsely available data on biomass utilization for developing countries. Specifically, the software used, the GCAM-EML is very user-friendly and is open source.

\subsubsection{GCAM Modelling}

As an integrated assessment model, GCAM provides the assessment of interrelated systems that are either human (economy, energy, etc.) or physical (climate change, water, etc.). It was developed by the Joint Global Change Research Institute (JGCRI). Furthermore, GCAM is a global model that represents the behavior of, and interactions between five systems: energy, water, agriculture, and land use, the economy, and climate [21, 22]. More so, according to the documentation on the model, the model has been used to produce scenarios for national and international assessments ranging from the very first IPCC scenarios through the present Shared Socioeconomic Pathways [23] and amongst others, 
has also used to model and analyze petroleum products in the Korean energy system [21] and to study how biomass utilization in the Ethiopian energy system could be reduced [8].

The model permits users to explore various scenarios and projects their impacts on possible future conditions. Although the outputs of the model are not forecasts, they make it possible to analyze the possible impacts of the various scenarios [23]. In this way, GCAM takes in external assumptions on population, economic activity, technology, and policies, and then computes their implications on key decision-relevant outcomes like commodity prices, energy use, land use, water use, emissions, and pollutant concentrations [23]. Two systems of GCAM that intervene in our study are the macroeconomic and energy systems.

\subsubsection{Macroeconomy system}

The macroeconomic system of GCAM is run by its socioeconomic module, which serves to provide a set of projections of population and GDP, which in turn drive projections of $\mathrm{CO}_{2}$ and other relevant climate-forcing emissions that are inputs for the calculation of a baseline climate trajectory [24]. This module takes population and labor productivity assumptions as inputs and produces regional gross domestic product and regional population values as outputs for the other modules. The macroeconomy sets the scale of economic activity in GCAM [23] and this is done by calculating the GDP of a future year. The values of the population are directly inputted into the model, while that of the GDP must be calculated as a function of population, labor force participation, and labor productivity, using Equation (1) below [21]

$$
i_{t}=\gamma \times L F_{t} \times L P_{0}\left(1+l p_{t p}\right)^{t p}
$$

where $i_{t}, l p_{t p}, L P_{0}, \gamma$, and $L F_{t}$ are the GDP of a specific period $t p$, labor productivity growth for the period, labor productivity in the base year, a coefficient calibrated at the base year, and the labor force participation, respectively.

\subsubsection{Energy System}

The energy system of GCAM includes a detailed representation of energy production, transformation, distribution, and use, in each of 32 geopolitical regions [25]. It is a detailed representation of the sources of energy supply, modes of energy transformation, and energy service demands such as passenger and freight transport, industrial energy use, and residential and commercial energy service demands.[23] The overall structure of the energy system can be thought of as consisting of three main elements: energy resources, energy transformation, and final energy demands [26]. Energy systems demand bioenergy from agriculture and land systems and water from water systems and reports demand and supplies of energy forms as well as emissions of greenhouse gases, aerosols, and other short-lived species [23]. Each technology used to provide the various energy services is characterized by its capital and operating costs, efficiencies, and fuel requirements [27]. The primary data source for all energy flow volumes in the historical years is the IEA Energy Balances [4]. The socioeconomic drivers - population and income determine the demand for floor space in all 32 regions of GCAM [27]. The future evolution of building energy use is greatly influenced by changes in floor space, the level of building service per unit of floor space, and fuel and technology choices by consumers; meanwhile the demand of generic services per unit flow space, $d$ given by Equation (2) [28].

$$
d_{t}=k \times s\left[1-\exp \left(-\frac{\ln 2}{\mu} \frac{I_{t}}{P_{t}}\right)\right]
$$

where $s$ is the level of demand satiation, $k$ is a calibration parameter, $\mu$ is the per-capita GDP at $50 \%$ of the satiation level, $I$ is per capita GDP, and $\mathrm{P}$ is the price of the service. The term I/P relates to the affordability of a service [19], and shows that the higher the affordability the lower the service demand and vice-versa.

To satisfy this service demand, GCAM uses the logit function presented in (3) to choose amongst the competing technologies. This provides a possibility to not only depend on choosing the lowest price, 
but also on the technology's fuel price elasticity [21, 29], to create a mix where various technologies could be represented. Thus, the share of technology $t$ allocated to satisfy the demand of an energy service where various technologies compete is given by the following equation.

$$
S_{t}=\frac{b_{t} \times P_{t}^{r_{p}}}{\sum_{j}\left(b_{j} \times P_{j}^{r_{p}}\right)}
$$

where $P_{t}$ is the price of (or the cost of providing an energy service by) technology $t, r_{p}$ is price exponent also known as the logit exponent (or price elasticity for technology $t$ ), $b_{t}$ is the base share of technology $t$.

The cost of this service depends on the set of technologies that would be chosen by the logit function ((3). Meanwhile, the cost of a technology to supply a sector is determined by the fuel price and the levelized non-energy cost, and this is given by Equation (4) [21].

$$
c_{s, h, t}=P_{f, t} \times \operatorname{coeff}_{s, h, t}+\lambda_{s, h, t}
$$

where $c_{s, h, t}, P_{f, t}$, coeff $f_{s, h, t}, \lambda_{s, h, t}$, and $f$ are the cost of the service $s$ that is supplied by technology $h$, price of fuel that is used by technology $h$, coefficient is defined as coeff $=1 /$ efficiency, levelized non-energy cost (input cost), and the type of fuel that supplies end-use energy technologies (electricity, refined liquids, gas, biomass, etc.), respectively.

Since the cost of energy service is obtained from the cost of providing the service from each of the individual technologies that are used to provide the service, this means that since multiple technologies are used to provide the cooking service, the cost for cooking service, $P_{c}$, for example, is calculated using as an average of all the various technology costs, weighted by their various demands, as shown in equation (5) [27] [30].

$$
P_{C}=\frac{\sum_{j} P_{C, j, t} d_{C, j, t}}{d_{C}}
$$

where $\mathrm{j}$ represents all the technologies that were used to satisfy the service. In terms of the technology shares, the above cost is given by the equation below.

$$
P_{C}=\sum_{h} S_{s, h, t} \times c_{s, h, t}
$$

where $S$ is the share of each technology, $\mathrm{P}_{\mathrm{c}}$, the price of service demand and $c$ is the cost of the technology to supply energy service $s$.

The final quantity of fuel input consumed to provide the energy service demand depends on the efficiency of the technology. used as demonstrated by Equation (8). This means that for a constant energy service per unit floor space demand, the quantity of fuel input of the technologies that are chosen is inversely proportional to the technology's efficiency.

\subsubsection{GCAM - EML}

The model was run using the GCAM-EML software developed by the Energy Modelling Laboratory (EML) of Ajou University. The software uses prepared workspaces in XML format containing the country-specific data of the GCAM data system and various scenario files as input and runs the scenarios using the GCAM core. Specific data for the energy system of Cameroon was prepared by the EML based on data by the IEA. The data for the various scenarios were inputted in the scenario files and run in the prepared workspace. The results were extracted as tables and analyzed using the MS Excel software.

\subsubsection{Affordability Evaluation}

The affordability of an energy service depends on the cost (or price) of the energy service or the fuels used by the various technologies as shown in Equation (6). To evaluate the affordability of a fuel, 
which is the ratio of the price of a commodity to the average income of a consumer of that commodity, we make use of the affordability index [19], which is the ratio of the affordability of a commodity compared to the reference affordability. If the index goes beyond a hundred percent, that commodity is said to be less affordable and vice-versa. In this study, we will use the affordability of fuels in the reference scenario as a base to calculate the indices, using the below formulation derived from [19] and [31]. Affordability $A_{f}=($ Price P) / (Income I).

$$
\text { Affordability Index } A_{I, f, \text { scen }}=\frac{A_{f, \text { scen }}}{A_{f, \text { ref_scen }}}
$$

where $A_{l, f, s c e n}$ is the affordability index of a fuel $\mathrm{f}$, in a scenario, $A_{f, s c e n}$ is the affordability of the fuel in a scenario, and $A_{f, r e f s, s e n}$ is the affordability of a fuel type in the reference scenario.

\subsubsection{Fuel Efficiency Evaluation}

Concerning the efficiency of biomass utilization technologies for various fuels, a fuel type could be consumed with different efficiencies depending on the type of technology that is applied in its utilization as demonstrated by various authors [13],[14],[15] (Table 1 and Table 2). These values agree closely with the data published by the World Bank [32].

The average biomass utilization efficiency can be evaluated by considering the various fuels that are used in the household. The average biomass utilization efficiency is calculated by considering the total biomass chemical energy input and the total thermal energy output [33], [14], as shown by Equation (8).

$$
\eta_{B U}=\frac{\sum_{i} \eta_{i} Q_{i}}{\sum_{i} Q_{i}}
$$

where $\eta_{B U}, \eta_{i}$, and $Q_{i}$, represent the average efficiency, the efficiency of individual technologies, and the quantity of fuel consumed using the individual technologies.

An evaluation of the efficiency of biomass to fuel transformation technologies shows results ranging from about $25 \%$ to about $90 \%$ [14, 34]. Table 1 shows some efficiencies for intermediary fuels production efficiencies.

Table 1: Biomass to Fuel Efficiencies for various Transformation Technologies

\begin{tabular}{|c|c|c|c|c|c|}
\hline Feedstock & Biofuel & Unit & Technology & $\begin{array}{c}\text { Efficiency } \\
(\%)\end{array}$ & $\begin{array}{c}\text { Base } \\
\text { Value (\%) }\end{array}$ \\
\hline Corn, corn stove & Corn ethanol & Litre/kg dry & Fermentation & $46.4-50.1$ & $/$ \\
\hline $\begin{array}{c}\text { Wood, shells, oil } \\
\text { crops, etc. }\end{array}$ & $\begin{array}{c}\text { Hydrogen, } \\
\text { Methanol, } \\
\text { DME, FT- } \\
\text { diesel }\end{array}$ & $\mathrm{kg} / \mathrm{kg}$ & Gasification & $39-70$ & $/$ \\
\hline $\begin{array}{c}\text { Energy maize, ley } \\
\text { crops }\end{array}$ & $\begin{array}{c}\text { Methane, } \\
\text { butanol }\end{array}$ & $\begin{array}{c}\text { GJ/dry ton } \\
\text { or } \mathrm{m} / \mathrm{kg} \\
\mathrm{dry}\end{array}$ & Fermentation & $36.5-81.3$ & 36 \\
\hline \begin{tabular}{c} 
Lignocellulose \\
Electricity \\
\cline { 2 - 6 }
\end{tabular} & $\begin{array}{c}\mathrm{LHJ} / \mathrm{kg}) \\
\text { Electricity }\end{array}$ & $\begin{array}{c}\mathrm{LHV} \\
(\mathrm{MJ} / \mathrm{kg})\end{array}$ & BIGCC & $32-45$ & 32 \\
\hline Wood, shells, & Charcoal & $\mathrm{kg} / \mathrm{kg}$ & Carbonization & $42.6-90.8$ & 50 \\
\hline
\end{tabular}

Source: [14] 
In Cameroon, biomass transformation is mainly from firewood and other wastes into various forms of charcoal. Concerning technologies used for cooking, practical experiments by authors like Mainali et al, who worked for the case of China, and Sanga and Jannuzzi, who worked for the case of Tanzania, show that biomass fuel end-use can have values ranging from $10 \%$ to $65 \%[13,15,32]$. Table 2 presents the results of some studies and the base values that were consider in this study. The choice of the base values is based on the following:

- For biogas, LPG, kerosene, and electricity, we chose the average of the values presented by Malla [32], as these are most appropriate for the case of Cameroon as a developing country, where all these technologies are simply imported.

- For technologies that are locally produced like firewood stoves, which have non-standard values of efficiency, we choose the least value because, as very little work has been done by the Government of Cameroon to produce more efficient stoves, so the technologies used are still basic.

- As for charcoal, we use the efficiency value that has been presented by most authors. Also, some ameliorated charcoal stoves have been introduced in the Cameroonian market within the framework of the SIE4All program, so there is at this point a slight increase from the basic efficiency levels when it comes to charcoal.

Table 2: Some Fuel Types and their Efficiencies

\begin{tabular}{|c|c|c|c|c|c|c|}
\hline \multirow[b]{2}{*}{ Fuel } & \multirow[b]{2}{*}{ Unit } & \multirow{2}{*}{$\begin{array}{c}\text { Heat } \\
\text { Value } \\
\text { (MJ/unit) }\end{array}$} & \multicolumn{4}{|c|}{ Efficiency $(\%)$} \\
\hline & & & Sanga & Mainali & Malla & $\begin{array}{c}\text { Base Value } \\
\text { used }\end{array}$ \\
\hline Biogas & $\mathrm{m}^{3}$ & 23 & & 65 & $50-65$ & 57.5 \\
\hline LPG & $\mathrm{kg}$ & 47.31 & 55 & 60 & $40-70$ & 55 \\
\hline Kerosene & litre & 37.5 & 35 & & $35-55$ & 45 \\
\hline Electricity & $\mathrm{kWh}$ & 3.6 & 80 & 75 & 75 & 75 \\
\hline Charcoal (traditional stoves) & $\mathrm{kg}$ & 20.1 & 20 & 20 & $10-22$ & 20 \\
\hline Charcoal (efficient stoves) & $\mathrm{kg}$ & 20.1 & 35 & & $20-35$ & 20 \\
\hline Firewood (open fire or mud) & $\mathrm{kg}$ & 14.8 & 17 & 15 & $13-18$ & 13 \\
\hline Efficient Firewood stove & $\mathrm{Kg}$ & 14.8 & & & $23-40$ & 13 \\
\hline
\end{tabular}

Source: Extracted from [13], [32] and [15]

Due to lack of more data, we shall assume that cooking in the building sector is done mainly by firewood, charcoal, sawdust (associated herewith charcoal since they use a more advanced stove than firewood), and LPG. A minimal quantity of kerosene is used for cooking, but according to [35], kerosene is mainly used for lighting, and electricity for lighting and appliances. Furthermore, with time, electricity and biogas can be introduced into the mix.

\subsection{Data}

Within the scope of our study, the building sector is made up of residential and commercial sectors. GCAM uses IEA data for energy requirements. For socioeconomic data required for the various scenarios, the data would be obtained from the Cameroon Government's Vision 2035 document [36]. The document provides future GNI and population growth rates. The former is used with the help of the relationship determined by Daicon and Maha [37] to determine the GDP growth rates. Future values of both GDP and population are calculated based on the 2015 values presented by the World Bank's Development Indicators online tool [38]. GCAM uses economic data in 1990 USD, as a result, we used the USD Inflator [39] for inflation rates and the online tool Inflation Calculator [40], to calculate the 1990 values of various GDP values.

Here, the socioeconomic data comes from Cameroon's plan to grow the economy and control population growth according to Vision 2035. The resulting socio-economic data used are presented in Table 3 below. 
Table 3: Baseline socioeconomic data used in the Study (2015 - 2035)

\begin{tabular}{|l|c|c|c|c|c|}
\hline \multicolumn{1}{|c|}{ Elements } & 2015 & 2020 & 2025 & 2030 & 2035 \\
\hline Population Growth (\%) & 2.5 & 2.4 & 2.3 & 2.2 & 2.1 \\
\hline Population (million) & 23.30 & 26 & 29 & 33 & 36 \\
\hline GNI Growth rates & 7.1 & 10.3 & 10.5 & 11.2 & 9.9 \\
\hline GDP per Capita PPP (\$) & 3,261 & 5,324 & 8,771 & 14,913 & 23,908 \\
\hline Real GDP PPP (Billion \$) & 75.98 & 139.65 & 257.78 & 488.68 & 869.24 \\
\hline $\begin{array}{l}\text { GDP per capita MER (0.4PPP) } \\
\text { thousand \$) }\end{array}$ & 1.30 & 2.13 & 3.51 & 5.97 & 9.56 \\
\hline GDP PC MER (thousand \$1990) & 0.72 & 1.07 & 1.59 & 2.42 & 3.46 \\
\hline
\end{tabular}

Source: World Bank Development Indicators Web page [38] and [36], [40], [37], [39]

In Cameroon, biomass transformation is mainly from firewood and other wastes into various forms of charcoal. Concerning technologies used for cooking, practical experiments by authors like Mainali et al, who worked for the case of China and Sanga and Jannuazzi, who worked for the case of Tanzania, show that biomass fuel end-use can have values ranging from $10 \%$ to $65 \%[13,15,32]$. Table 4 below shows the results of these various studies and the base values that we will consider for this study. The choice of base values is based on the following:

- For biogas, LPG, kerosene, and electricity, we chose the average of the values presented by Malla [32], as these are most appropriate for the case of Cameroon as a developing country, where all these technologies are simply imported.

- For technologies that are locally produced like firewood stoves, which have non-standard values of efficiency, we choose the least value because, as very little work has been done by the Government of Cameroon to produce more efficient stoves, so the technologies used are still basic.

- As for charcoal, we use the efficiency value that has been presented the most by related authors. Also, some ameliorated charcoal stoves have been introduced in the Cameroonian market within the framework of the SIE4All program, so there is at this point a slight increase from the basic efficiency levels when it comes to charcoal.

Table 4: Some Fuel Types and their Efficiencies

\begin{tabular}{|c|c|c|c|c|c|c|}
\hline \multirow{2}{*}{ Fuel } & \multirow{2}{*}{ Unit } & \multirow{2}{*}{$\begin{array}{c}\text { Heat } \\
\text { Value }\end{array}$} & \multicolumn{4}{|c|}{ Efficiency (\%) } \\
\cline { 5 - 7 } & & MJ/unit) & Sanga & Mainali & Malla & $\begin{array}{c}\text { Base Value } \\
\text { used }\end{array}$ \\
\hline Biogas & $\mathrm{m} 3$ & 23 & & 65 & $50-65$ & 57.5 \\
\hline LPG & $\mathrm{kg}$ & 47.31 & 55 & 60 & $40-70$ & 55 \\
\hline Kerosene & $\mathrm{litre}$ & 37.5 & 35 & & $35-55$ & 45 \\
\hline Electricity & $\mathrm{kWh}$ & 3.6 & 80 & 75 & 75 & 75 \\
\hline Charcoal (traditional stoves) & $\mathrm{kg}$ & 20.1 & 20 & 20 & $10-22$ & \multirow{2}{*}{20} \\
\hline Charcoal (efficient stoves) & $\mathrm{kg}$ & 20.1 & 35 & & $20-35$ & \\
\hline Firewood (open fire or mud) & $\mathrm{kg}$ & 14.8 & 17 & 15 & $13-18$ & \multirow{2}{*}{13} \\
\hline Efficient Firewood stove & $\mathrm{Kg}$ & 14.8 & & & $23-40$ & \\
\hline
\end{tabular}

Source: [13], [32] and [15]

The energy-related data is that which established by the energy trend of the year 2015. The various scenarios are built on this baseline data, with only changes in the efficiencies of biomass transformation and utilization technologies. Two sets of scenarios were developed in this study namely: reference and alternative scenarios. 


\subsection{Scenario Development}

The future of an energy system is very difficult to predict since it depends on many unpredictable assumptions such as the behavior of energy consumers and how Governments choose to invest. However, the understanding of possible future developments of such complex systems can rather be assisted by a set of scenarios [41]. Scenarios are useful tools for investigating alternative future developments and their implications, for learning about the behavior of complex systems, and for policymaking [42]. In the GCAM system used, the baseline scenario is that presented by the SSP2 of the GCAM system. However, the narrative of the baseline scenario used for all the scenarios in this study is that which corresponds to the achievement of socio-economic development of the Vision 2035 plan by the Government of Cameroon [36]. Thus, the snapshots for the future are mainly based on the improvement of biomass technologies efficiency. Table 3 above presents the socio-economic data that applies to the various scenarios.

\subsubsection{Reference Scenario}

The reference scenario represented a case where no policy changes related to biomass utilization efficiency improvement in the building sector took place over the modeling period, causing the efficiency of biomass utilization to remain constant and equal to the base year values.

\subsubsection{Alternative Scenarios}

On the other hand, the alternative scenarios presented two levels of efficiency improvements, due to factors like advanced biomass technologies, policies, education, etc. These advanced biomass technologies include more advanced firewood and charcoal stoves, biogas digesters and stoves, mini gasifiers for residential use, etc. When these occupy an important part of the building energy system, the efficiencies of derived biomass and traditional biomass fuels could increase and eventually attain $25-30 \%$ and $35-45 \%$ respectively by the end of the year 2035, values which according to Mainali, Malla, and Sanga, $[13,15,32]$, are attainable and already in use. From these assumptions, Table 5 below presents the various scenarios.

Table 5: Developed Scenarios

\begin{tabular}{|c|c|c|c|c|}
\hline \multirow{2}{*}{ No. } & \multirow{2}{*}{ Scenarios } & Description & \multicolumn{2}{|c|}{ Efficiency assumptions by end year (2035) } \\
\cline { 4 - 5 } & & & Traditional biomass & Biomass \\
\hline 0 & GCAM & GCAM based & $12.5 \%$ & $25 \%$ \\
\hline 1 & Ref & Reference scenario & $13 \%$ & $20 \%$ \\
\hline 2 & Alt-1 & Lower efficiency & $\geq 25 \%$ & $\geq 30 \%$ \\
\hline 3 & Alt-2 & Higher efficiency & $\geq 35 \%$ & $\geq 45 \%$ \\
\hline
\end{tabular}

To achieve the above efficiency targets, the exponential growth function was used to derive the efficiency targets on a five-year step basis. The values were used to construct the various scenario files.

The various scenarios were run and the results were obtained and analyzed, namely: total energy input (fuel), fuel type consumption, commercial and residential energy consumption, carbon dioxide, and non-carbon dioxide emission, for the period from 2015 to 2035.

\section{Results}

\subsection{Total energy consumption}

The results show an increase in total energy consumption in the building sector throughout the modeling period for all scenarios. However, there is a very slight difference in the total energy 
consumption between the alternate scenarios. In the reference scenario, the total energy consumed by the building sector went from 5,645 to about 9,348.5 ktoe. In the alternate scenarios, the final values were 10,752 and 11,183 for Alt-1 and Alt-2 scenarios respectively. More so, a very slight difference in energy consumption is observed between the two alternate scenarios, as almost the same amount of energy is consumed in both scenarios. Figure 1 shows the trend in total energy consumption for the modeling period.

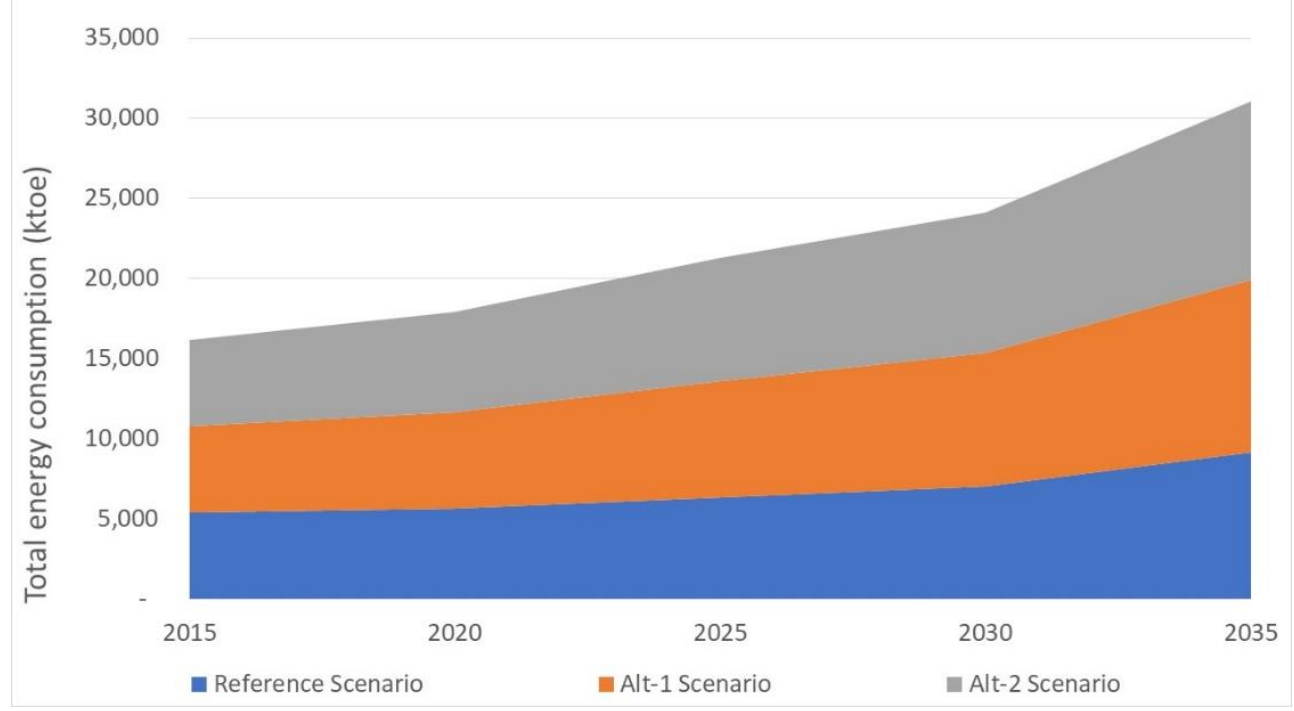

Figure 1: Building sector total energy consumption

\subsection{Consumption of various fuel types}

Figure 2 shows the result of increasing the efficiency of biomass and traditional biomass on the consumption of various energy sources. Biomass consumption rises till the end of the year 2035. This increase is highest with the Alt-2 scenario which has the highest efficiency increment, with the consumption peaking at about 3,343 ktoe of biomass in the year 2035. Following is the Alt-1 scenario, which attains a peak of about 2,639 ktoe in the year 2035 all against the reference scenario that peaked at 1810 ktoe (Figure 2a). The quantity of traditional biomass slightly increases and then constantly falls till the end of the modeling period. In the reference scenario, however, traditional biomass consumption constantly falls till the end, with no rise in consumption. There is almost no difference in the consumption of traditional biomass, as concerns the two alternate scenarios. Traditional biomass consumption moves from 3,775 to about 392, 937, and 930 ktoe in the reference, Alt-1, and Alt-2 scenarios respectively (Figure $2 \mathrm{~b}$ ). The consumption of refined liquids (kerosene and liquified petroleum gas) is seen to at first drop and then rise till the end of the modeling period. The alternative scenarios show a lower consumption compared to the reference scenario. In the reference scenario, the consumption of refined liquids goes from about $188 \mathrm{ktoe}$ to about $362 \mathrm{ktoe}$ in 2035. Meanwhile, in the Alt- 1 and Alt-2 scenarios, the same trend follows as in the reference scenario, attaining values of 319 and 279 ktoe respectively in the year 2035 (Figure 2c). Finally, the increase in the efficiency of biomassbased fuels does not seem to have a significant effect on the consumption of electricity, the alternative scenarios how a lower electricity consumption. In the reference case, electricity consumption goes from about 230 ktoe growing exponentially to about 32,000 ktoe. The alternative scenarios follow the same trend, ending at about 31,500 and 31,000 ktoe respectively for Alt-1 and Alt-2 scenarios (Figure 2Error! Reference source not found.d). 

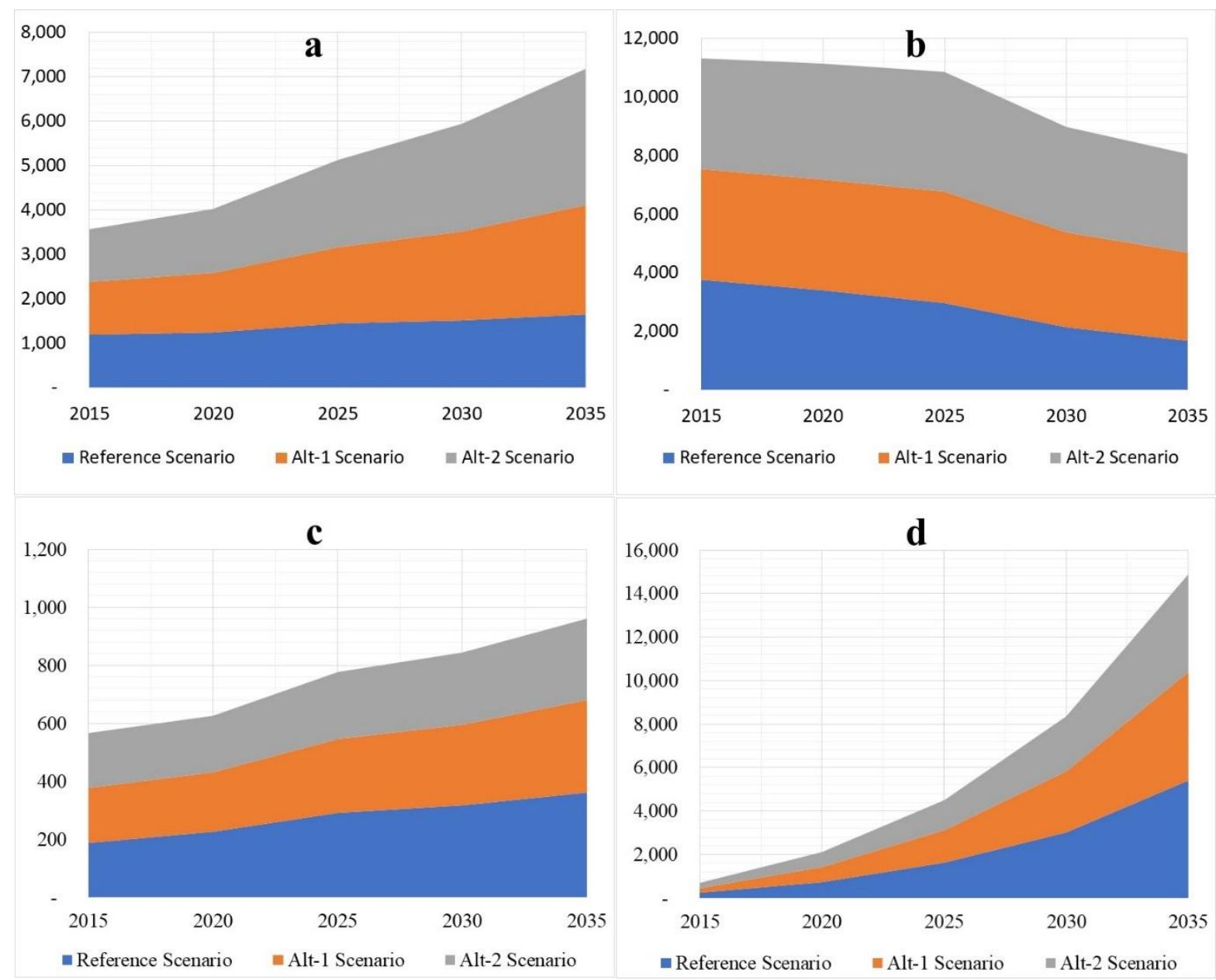

Figure 2: Consumption of various fuels by the building sector (ktoe) for the period 20152035: (a) biomass,

(b) traditional biomass, (c) refined fuels, and (d) electricity.

\subsection{Commercial and residential energy consumption}

The total energy consumption in the commercial sector is seen to gradually increase from the base year to the end of the modeling period. However, that for the residential sector is seen to fall slightly till 2030 and then rise. The residential sector took off at a value of 4,102 ktoe in the reference scenario, reduces to 3,185 ktoe in 2030, and finishes at about 4,412 ktoe in the reference scenario. For the Alt-1 and Alt-2 scenarios, there is an increase to 5,548 ktoe and 5411 ktoe respectively by the year 2030 (Figure 3a). On the other hand, the commercial sector shows less deviation from its energy consumption because of the increase in biomass efficiency compared to the residential sector. In the commercial sector, the total energy consumption rose from 1285 ktoe and finally attains 4,729 ktoe in the reference scenario, about 2,204 ktoe in the Alt-1 scenario, and 5,412 ktoe in the Alt-2 scenario (Figure 3b). 


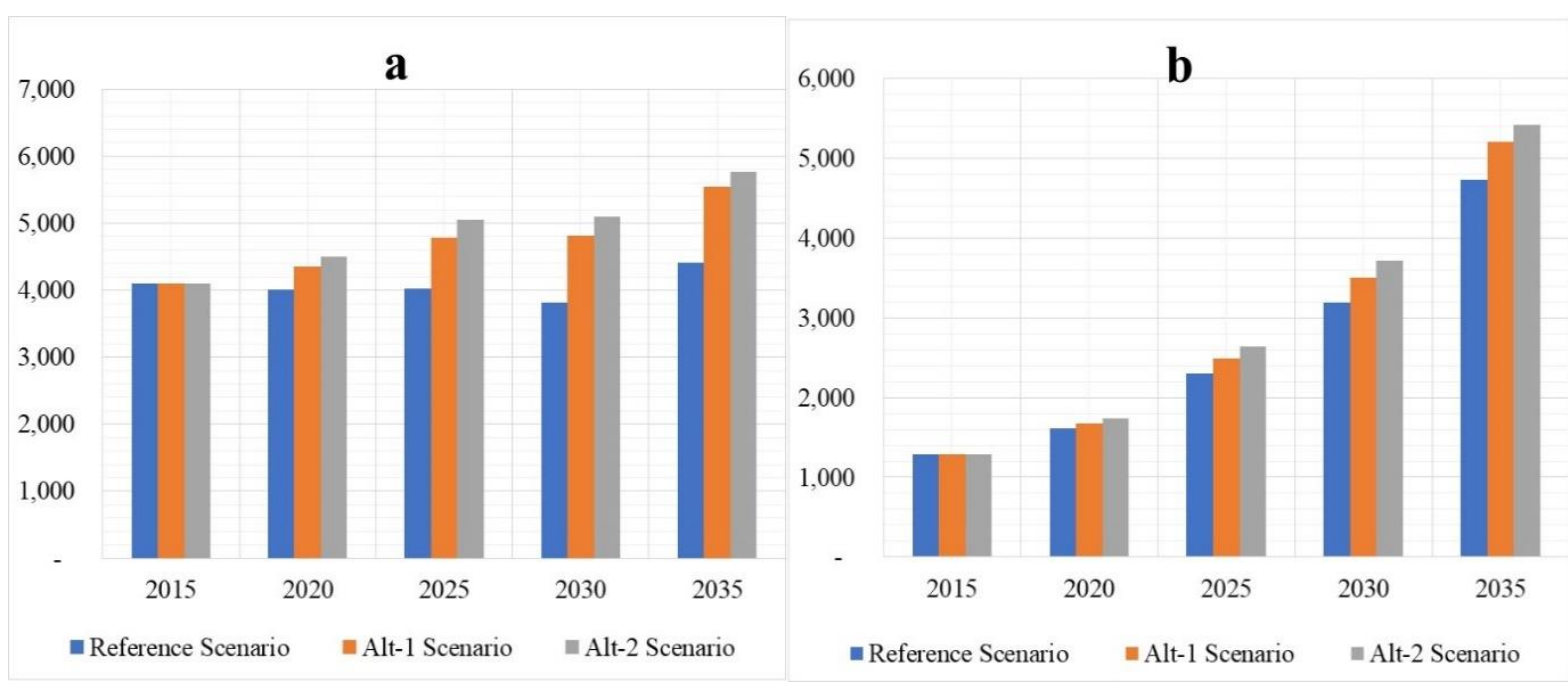

Figure 3: Total energy consumption (ktoe) by (a) the residential and (b) the commercial sectors

\subsection{Carbon dioxide $\left(\mathrm{CO}_{2}\right)$ and non- $\mathrm{CO}_{2}$ emissions}

The results show that the trend of $\mathrm{CO} 2$ emissions in the building sector follows the trend of biomass-based fuels. In the reference scenario, the quantity of emission starts to rise from 1.3 MTC and attains a maximum of 1.9 MTC by the year 2035. In the Alt-1 and Alt-2 scenarios, emissions of CO2 emissions attain 2.6 MTC and 3.2 MTC respectively at the end of the modeling period (Figure 4a). On the other hand, non-CO2 emissions are not significantly affected by the improvement of biomass efficiency, with the emissions moving from 0.7 MTC and growing to 3.41, 3.57, and 3.64 MTC in the reference, Alt- 1 and Alt-2 scenarios respectively (Figure $4 \mathrm{~b}$ ).

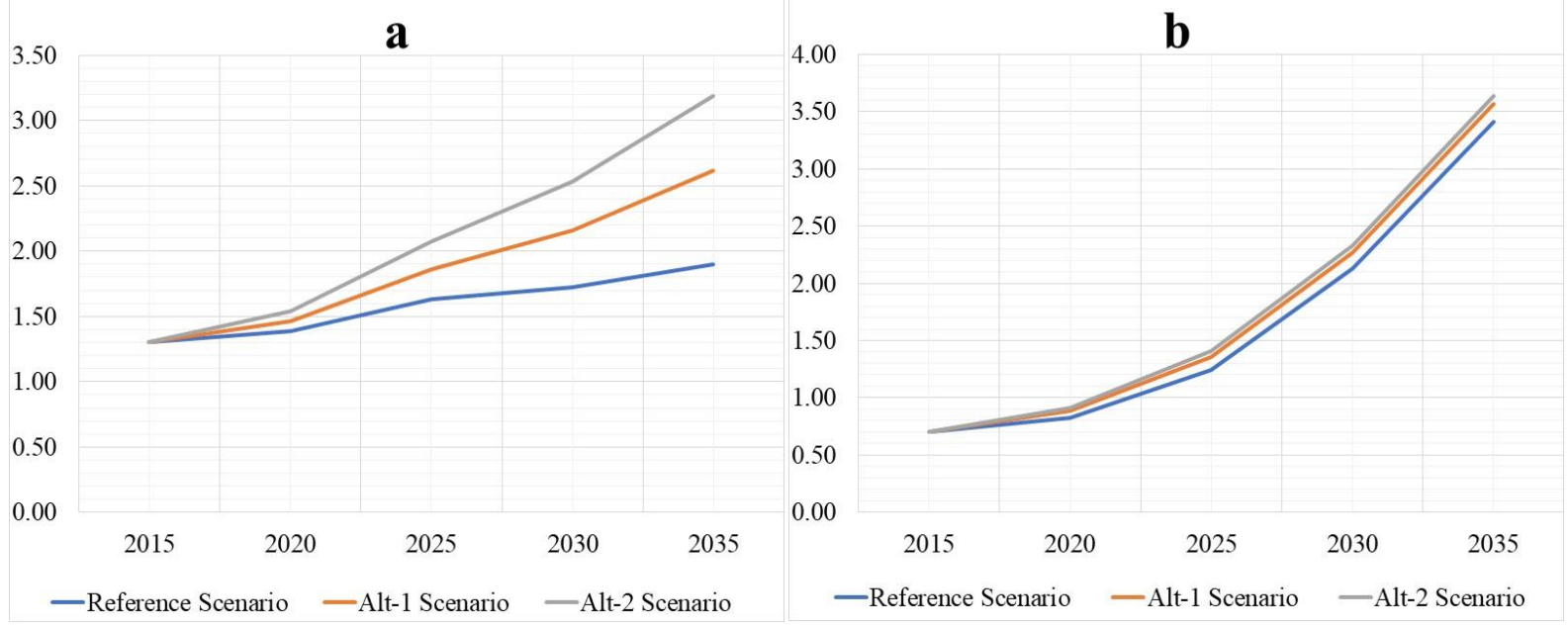

Figure 4: Level of emissions (MTC) of (a) $\mathrm{CO}_{2}$ and (b) non- $\mathrm{CO}_{2}$ gases for the period 2015-2035

\subsection{Cost of building energy fuels}

The results show an effect on the cost of biomass and traditional biomass (Figure 5

Figure $5 a, b$ ). The prices of electricity, kerosene, and LPG remain unperturbed (Figure $5 c, d$ ). In the reference scenario, the prices of both derived biomass and traditional biomass were constant. However, the alternative scenarios gave a considerable drop in prices, falling as low as about 36.59 and 2.891975 \$/GJ for the Alt-1 scenario and 27.17 and 2.321975 \$/GJ for the Alt-2 scenario. 


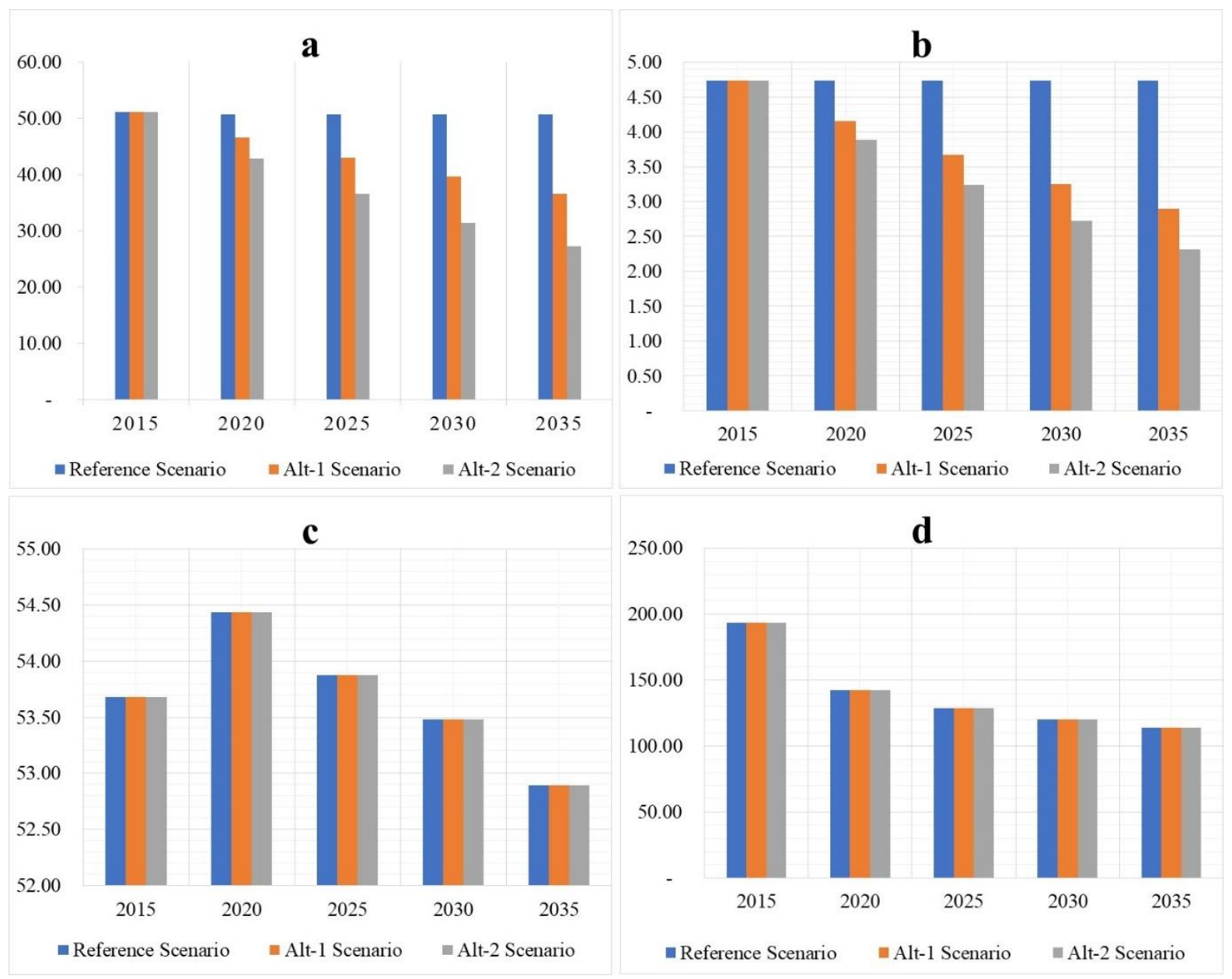

Figure 5: Cost of fuels (1975\$/GJ) for (a) biomass, (b) traditional biomass, (c) refined fuels, and (d) electricity for the period 2015-2035

\section{Discussions}

The increase in the efficiency with which basic forms of biomass fuels are consumed, shows an impact on the consumption of various fuels, their affordability, and $\mathrm{CO} 2$ emission, in the building sector. In this work, the hypothesis investigated is: increasing the efficiency of certain biomass technologies (those that use traditional biomass (firewood, leaves, dung) and derived biomass (charcoal, sawdust)) will not only lead to lower biomass fuel consumption and reduce CO2 emission but will also increase the availability of other energy forms of energy such as gas from biodigesters, electricity from syngas and biogas derived from biomass. In addition, the concept of the affordability (prices) of the building sector energy forms was investigated. The results of these investigations presented in the previous chapter are explained in the following paragraphs.

\subsection{Final Energy Consumption Trend}

As the per capita income increases [36], the demand for energy services naturally increases. However, Figure 1 shows that the higher the efficiency of biomass technologies, the higher the per capita energy consumption. Since the main driver of energy consumption is affordability, at lower income levels, and as the prices of biomass-based fuels fall with increase efficiency and the prices of electricity and refined liquids fall across the modeling period (Figure 5), the consumption of the various fuels increases. However, the energy consumption increasing with the increase in biomass efficiency is because, as the prices of biomass fuels fall, more biomass is consumed in large quantities, causing an overall increase in energy consumed. Although the improvement of the efficiency of biomass technologies leads to lower consumption of other fuels, the margin with which more biomass and 
traditional biomass is consumed above the reference scenario is much higher, leading to an overall increase in energy consumed.

\subsection{Building Sector Fuels Consumption Trend}

As explained above, the prices of biomass-based fuels fall with the increase in efficiency, especially towards the end of the modeling period (Figure 5). This means that the fuels become more affordable. As a result, consumers will tend to consume more biomass (Figure 2). This leads to a slight reduction in the use of other fuels like refined liquids and electricity, as the biomass efficiency increases. Notwithstanding, even though there is a high level of biomass technology efficiencies, at higher income levels, less and less biomass-based fuels are consumed compared to the initial quantities. This is because, at a certain income level, individuals start preferring to use more modern fuels and gradually reduce or abandon the use of biomass-based fuels in preference to refined liquids and electricity. For traditional biomass, this happened much earlier compared to derived biomass. However, even at higher income levels, the higher the efficiency, the higher the quantity of derived biomass used in the building sector. From Figure 2, we see that at higher efficiencies, derived biomass will persist as energy fuel in the far future in coherence with studies by Yurnaidi [21], while traditional biomass will not, even with much higher efficiencies. However, the consumption of less refined liquids and electricity due to the increase of biomass fuel efficiencies could be looked upon as an advantage since more energy will be available for the industrial sector, which very much needs these fuels in greater quantities.

More so, the reduction of derived biomass and traditional biomass does not necessarily imply the total disappearance of the fuel from the energy system. Rather, these fuels will now become available not for direct consumption, but transformation into other forms of energy like electricity, biodiesel, methanol, syngas, and even hydrogen.

\subsection{Biomass Efficiency and Emissions}

The increase in $\mathrm{CO}_{2}$ emission observed Figure 4a is associated with the increase in biomass consumption. These results are contrary to the case for the US [43],[44],[45], who used statistical methods for their investigations to demonstrate that increased biomass consumption reduced the level of $\mathrm{CO} 2$ emission for the period from 1973 to 2016. Furthermore, as biomass efficiency increases leading to more biomass consumption, the rate of consumption of refined liquids, hence $\mathrm{CO}_{2}$ emission from refined liquids reduce. However, the higher polluting nature of biomass-based fuels besides their higher consumed quantities, ensures that there is an overall increase in $\mathrm{CO}_{2}$ emission. As for non- $\mathrm{CO}_{2}$ emissions, we see that increasing biomass efficiency, does have a considerable impact on non- $\mathrm{CO}_{2}$ emissions. However, higher biomass consumption at higher efficiencies produces more non-CO2 pollutants.

\subsection{Biomass Efficiency and Fuel Affordability}

Based on the definition of affordability index as presented in [19] and [31], and indexing the affordability of the various fuels on the reference scenario, we calculated the affordability index of the various fuels based on the Alt- 1 and Alt-2 scenarios using Equation (7). Since the increasing efficiency does not affect the prices of refined fuels and electricity, we see that the affordability analysis only affects derived biomass and traditional biomass. Figure 7 shows the variation of affordability across the various scenarios for these two fuels. The figure shows that for both fuels as the efficiency increases, so does the affordability index fall below $100 \%$, showing that the fuel is becoming more affordable.

For biomass fuel (Figure 7a), the affordability index falls from $100 \%$, which is the reference scenario value and attains a value of $72 \%$ and $54 \%$ for the Alt- 1 and Alt-2 scenarios, respectively. In the same way, for traditional biomass (Figure $7 \mathrm{~b}$ ), the index falls to $61 \%$ and $49 \%$ respectively for the Alt- 1 and Alt-2 scenarios. Therefore, the higher the efficiency of the technology used for the consumption of a particular biomass fuel, the lower the affordability index compared to the reference scenario, and the lower the price of that fuel. 


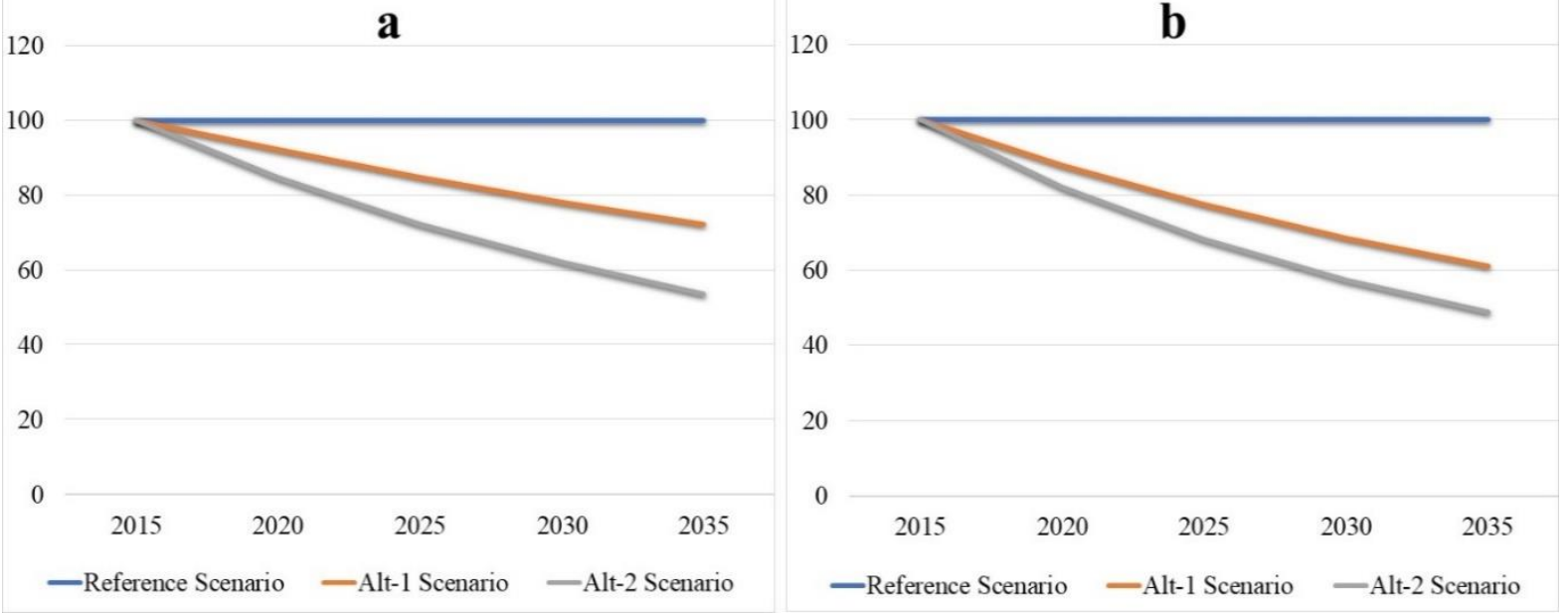

Figure 7: Variation of the affordability index for (a) biomass and (b) traditional biomass for the period 20152035

\section{Conclusion}

The building sector energy consumption patterns are one of the things that policy instruments need to consider. This study investigated how the efficiency of biomass technologies influence these patterns. The results show that an increase in the socioeconomics of a country leads to an increase in the consumption of various fuels, biomass inclusive. However, the increased use of biomass fuels does not only cause health challenges to women and girls who are the most vulnerable but also leads to increase deforestation in most developing countries in the tropical regions of the globe. Therefore, the sector needs much regulation by appropriate policies.

Furthermore, the results show that electricity and refined oils will be the main building sector energy forms in the future. Therefore, policies stimulate stakeholders to invest in the provision of these energy forms are needed. The source of these energy forms need not necessarily be from the conventional sources only, but also from the decreasing quantities of biomass observed in the later years. This shows the need for more research and investment in biomass transformation technologies.

In this same line, the results show that like traditional biomass, the quantity of derived biomass consumed is also considerable. Therefore, energy policies should encourage the transformation of traditional biomass into derived biomass, as these present higher efficiencies and are more energyintensive and are more preferred in the future, compared to traditional biomass.

Concerning emissions, the consumption of biomass fuels increased $\mathrm{CO} 2$ emissions. However, if the quantity of energy consumed from biomass was from either refined oils or electricity, especially when a large percentage of the electricity is produced by thermal plants using fossil fuels, the overall emissions could be more. Therefore, $\mathrm{CO} 2$ emission reduction programs that target biomass consumption reduction in the building sector will be less effective compared to those that target the transformation of biomass into modern forms of energy, thus improving their conversion efficiency in line with the recommendations of the IEA and the RETD [46].

Further research is needed to investigate biomass consumption in the industrial sector and possibly completely model the energy system, to investigate the influence of any fuel or factor on all sectors. One of the difficulties of this study is the lack of data related to the building sector energy consumption pattern for Cameroon. More so, studies and surveys with details including sub-regional data, building types, and appliances, would be very instrumental to enrich the conclusions of this study and would enable better grass-root decision-making. Such studies include: detailed building sector disaggregation, building sector in-depth energy surveys, modeling the transport and industrial sectors; a complete representation of the country's energy system with a computerized model like GCAM as model-based decision making tool; further studies related to the various aspects of the energy system namely: water system, land use system, energy consumption patterns, demographic and economic distribution of the country. 


\section{Data Availability}

The GCAM dataset created by the Energy Modeling Laboratory of Ajou University for Cameroon and updated with specific data for Cameroon can be found at https://github.com/ebakojoseph/gcamCameroon_dataset/blob/main/workspaces_Cameroon.zip

The GCAM-EML software package can be downloaded from: http://eml.ajou.ac.kr/eml/PublicSoftware/setup.exe

\section{References}

1. UNIDO, Energy, Development and Security: Energy issues in the current macroeconomic context. 2018.

2. Kruyt, B., et al., Indicators for energy security. 2009: p. 1.

3. UNDP and WB, Energy Issues and Options in Thirty Developing Countries, in UNDP/World Band Energy Assessmennt Program. 1984. p. iv-17.

4. IEA, Energy Balance for Cameroon. 2017, International Energy Agency.

5. Laouan, M.L. and A.J. Ndjinang, Energy sector of Cameroon, in Africa Review. 2019. p. 34-45.

6. SNH, SNH 2017 Annual Report. 2018: p. 30-33.

7. Mulugetta, Y., Energy in Rural Ethiopia: Consumption Patterns, Associated Problems, and Prospects for a Sustainable Energy Strategy. Energy Sources, 1999.

8. Yurnaidi, Z. and S. Kim, Reducing Biomass Utilization in the Ethiopian Energy System: A National Modeling Analysis. Energies, 2018.

9. Pachauri, S., An analysis of cross-sectional variations in total household energy requirements in India using micro survey data Energy Policy, 2004. 32.

10. Capareda, S.C., Introduction to Biomass Energy Conversions. 2014: p. 69-72.

11. Abanda, F.H., Renewable energy sources in Cameroon: Potentials, benefits and enabling environment. Renewable and Sustainable Energy Reviews, 2012. 16: p. 4557-4562.

12. Gwavuya, S.G., et al., Household energy economics in rural Ethiopia: A cost-benefit analysis of biogas energy. Renewable Energy, 2011.

13. Sanga, A. and G. Jannuzzi, Impacts of efficient stoves and cooking fuel substitution in family expenditures of urban households in Dar es Salaam, Tanzania. 2005.

14. Huang, W.-D. and Y.H.P. Zhang, Energy Efficiency Analysis: Biomass-to-Wheel Efficiency Related with Biofuels Production, Fuel Distribution, and Powertrain Systems. PLoS ONE, 2011. 6(7): p. e22113.

15. Mainali, B., S. Pachauri, and Y. Nagai, Analyzing cooking fuel and stove choices in China till 2030 Analyzing cooking fuel and stove choices in China till 2030. Journal of Renewable and Sustainable Energy, 2012. 4: p. 31805-114503.

16. Pachauri, S. and L. Jiang, The household energy transition in India and China Energy Policy, 2008. 36.

17. Tucho, G.T. and S. Nonhebel, Bio-Wastes as an Alternative Household Cooking Energy Source in Ethiopia. Energies, 2015.

18. Wolde-Ghiorgis, W., Renewable energy for rural development in Ethiopia: the case for new energy policies and institutional reform. Energy Policy, 2002. 30.

19. Kenton, W. Affordability Index. 2020 [cited 2020 20/11]; Available from: https://www.investopedia.com/terms/a/affordability-index.asp.

20. Calvina, K., et al., The SSP4: A world of Deepening Inequality. Global Environmental Change, 2016. 42: p. 148-152.

21. Yurnaidi, Z., A Modeling and the Analysis of Petroleum Products in Korean Energy System Using Integrated Assessment Mode, in Department of Energy Systems Research. 2016, Ajou University, South Korea.

22. Institute, J.G.C.R., GCAM v5.2 Documentation: Agriculture, Land-Use, and Bioenergy.

23. JGCRI. GCAM Model Overview. [Web Article] 2020; Available from: http://jgcri.github.io/gcamdoc/overview.html (accessed on the 03/06/2020).

24. National Academies of Sciences, E., and Medicine Valuing Climate Damages: Updating Estimation of the Social Cost of Carbon Dioxide. The National Academies Press, 2017: p. 10-41.

25. Calvin, K., et al., GCAM v5.1: Representing the Linkages between Energy, Water, Land, Climate, and Economic Systems. Geoscientific Model Development, 2019. 12(2): p. 677-698.

26. JGCRI, GCAM v5.2 Documentation: GCAM Energy System. 2020. 
27. Clarke, L., et al., Effects of Long-term Climate Change on Global Building Energy Expenditures. Energy Economics, 2018.

28. JGCRI. GCAM V5.3 Documentation - GCAM Energy System. 2020 [cited 2020 28/08.2020]; Available from: https://jgcri.github.io/gcam-doc/energy.html.

29. Brenkert, A.L., et al., Model Documentation for the MiniCAM. 2003, Office of Scientific and Technical Information (OSTI).

30. Clarke, J.F. and J.A. Edmonds, Modelling Energy Technologies in a Competitive Market. Energy Economics, 1993: p. 123-129.

31. ACEEE, Understanding Energy Affordability, D.o. Energy, Editor. 2020.

32. Malla, S. and G.R. Timilsina, Household Cooking Fuel Choice and Adoption of Improved Cookstoves in Developing Countries, in Policy Research Working Paper. 2014, World Bank.

33. Petterson, M.G., What is energy efficiency? - Concepts, Indicators and Methodological Issues. Energy Policy, 1996. 24: p. 377-390.

34. DEMIRBAS, A., Sustainable Charcoal Production and Charcoal Briquetting. Energy Sources, 2009. 31: p. 1694-1699.

35. MINEE, Energy Balance Sheet of Cameroon, R.E.a.E.M.-E.I.S. Unit, Editor. 2018.

36. MINEPAT, Cameroon Vision 2035. 2009.

37. Daicon, P.-E. and L.-G. Maha, The Relationship between Income, Consumption and GDP: A Time Series, Cross-Country Analysis, in 2nd Global Conference on Business, Economics, Management and Tourism, 3031 October 2014. 2015, Procedia Economics and Finance: Prague, Czech Republic. p. 1535-1543.

38. World-Bank. World Bank Developing Indicators. 2020 30/07/2020]; Available from: https://databank.worldbank.org/source/world-development-indicators.

39. Koema. US Inflator Forecast: 2020, 2021 and Long Term to 2060 - Data and Charts. USDA US Inflation, Long Term Forecast 2020 16/04/2020 [cited 2020 15/12]; Available from: https://knoema.com/kyaewad/us-inflationforecast-2020-2021-and-long-term-to-2060-data-and-charts\#.

40. Webser, I. Inflator Calculator. 2020 [cited 2020 15/12]; Available from: https://www.officialdata.org/.

41. Riekkola, A.K., National Energy System Modelling for Supporting Energy and Climate Policy Decisionmaking: The Case of Sweden. 2015.

42. Nakicenovic, N. and A. Gritsevskyi, Modeling Uncertainty of Induced Technological Change. Energy Policy, 2000. 28: p. 907-921

43. Kim, G., S.-K. Choi, and J.H. Seok, Does biomass energy consumption reduce total energy CO2 emissions in the US? journal of Policy Modeling, 2020. 42: p. 953-967.

44. Kampman, B., et al., BUBE: Better Use of Biomass for Energy, in Background Report to the Position Paper of IEA RETD and IEA Bioenergy. 2010.

45. Bilgili, F., The impact of biomass consumption on $\mathrm{CO} 2$ emissions: Cointegration analyses with regime shifts. Renewable and Sustainable Energy Reviews, 2012. 16: p. 5349-5354. 